\title{
Potencial alelopático de Bidens pilosa e Senna occidentalis na germinação e desenvolvimento de plântulas de gergelim
}

\author{
Karoline Fernanda Silva Amaral ${ }^{1}$, Andréa dos Santos Oliveira ${ }^{1}$, Tanismare Tatiana de Almeida ${ }^{1 *}$
}

\begin{abstract}
RESUMO: Objetivou-se nesta pesquisa avaliar o potencial alelopático dos extratos de folhas de fedegoso e picão preto na germinação e desenvolvimento de plântulas de gergelim. Para obtenção do extrato, as folhas colhidas foram secas em estufa por 24 horas a $50^{\circ} \mathrm{C}$, trituradas e adicionado água na proporção de $1 \mathrm{~g} / 10 \mathrm{~mL}$. Essa mistura foi mantida em frasco pelo período de 24 horas e diluída nas concentrações de 10,30,50 e 70\%. O delineamento experimental foi inteiramente casualizado, no esquema fatorial de 2 x 5 (espécies x concentrações $0,10,30,50$ e 70\%) e quatro repetições. Após a montagem do teste de germinação as sementes foram mantidas em BOD com fotoperíodo de 12 horas e temperatura de $25^{\circ} \mathrm{C}$. Juntamente com a germinação foram realizadas contagens diárias para cálculo do índice de velocidade de germinação e ao final foram medidos o comprimento de hipocótilo e radícula $(\mathrm{cm})$ das plântulas normais, evidenciando que o extrato de picão preto inibe a germinação e vigor de sementes de gergelim em concentrações superiores a 30\%. No caso do fedegoso pode-se inferir que o efeito alelopático é maior que o picão, uma vez que, afeta a germinação a partir da concentração de $10 \%$.
\end{abstract}

Palavras-chave: alelopatia, vigor, competição

\section{Allelopathic potential of Bidens pilosa and Senna occidentalis in the germination and development of sesame seedlings}

\begin{abstract}
It was aimed in this research to evaluate the allelopathic potential of the extracts of fedegoso (Cassia occidentalis L.) and picão preto (Bidens pilosa) leaves in the germination and development of sesame seedlings. For obtaining of the extract, the harvested leaves were dried in an oven for 24 hours at $50{ }^{\circ} \mathrm{C}$, crushed and water was added in the proportion of $1 \mathrm{~g} / 10 \mathrm{~mL}$. This mixture was kept in a flask for 24 hours and diluted at concentrations of 10,30,50 and $70 \%$. The experimental design was completely randomized, in a $2 \times 5$ factorial scheme (species x concentrations 0 , $10,30,50$ and $70 \%$ ) and four replications. After setting up the germination test, the seeds were kept in BOD with a photoperiod of 12 hours and at temperature of $25{ }^{\circ} \mathrm{C}$. Along with germination, daily counts for the calculation of the germination speed index were conducted and at the end, the length of hypocotyl and radicle $(\mathrm{cm})$ of the normal seedlings were measured, showing that the extract of Bidens pilosa inhibits the germination and vigor of sesame seeds at concentrations greater than $30 \%$. In the case of the Cassia occidentalis L., it can be inferred that the allelopathic effect is greater than that of the picão preto since it affects the germination from the concentration of $10 \%$.
\end{abstract}

Keywords: allelopathy, vigor, competition

\section{INTRODUÇÃO}

É sempre um desafio para o produtor o controle de plantas daninhas na lavoura. A diversidade dessas plantas na área de cultivo pode comprometer a produção em função da interferência da ação de aleloquímicos que pode ser benéfica ou não para a cultura de interesse. Desde a germinação até o final do ciclo o acompanhamento é importante a fim de avaliar a interferência da planta daninha na cultura.

Toda planta possui aleloquímicos em diferentes locais, concentrações e composições, atuando na defesa e na proteção do vegetal. A produção destas substâncias é variável e influenciada por uma série de fatores, como temperatura, precipitação, umidade e variação sazonal, que causam alterações no metabolismo primário e secundário do vegetal (ARAÚJO, 2016).

Esses compostos podem ser dispersos no ambiente por volatilização, exsudação radicular, lixiviação etc., provocando alterações nas estruturas física e química da composição biótica e abiótica do solo. Isso dificulta as atividades metabólicas do vegetal afetando a germinação, desenvolvimento e reprodução (FERREIRA; ÁQUILA, 2000; ARAÚJO, 2016). Assim como outras culturas, o gergelim é sensível à concorrência das plantas daninhas principalmente no estabelecimento inicial no campo, que é mais lento quando comparado ao das invasoras Bidens pilosa L. (picão preto) (ARRIEL et al., 2009) e Senna occidentalis L. (fedegoso) (CÂNDIDO et al., 2010).

O picão preto é uma planta daninha bastante agressiva, encontrada principalmente durante a primavera e verão. Além de competir com a cultura por nutrientes, serve também como hospedeira para pragas (RABÊLO et al., 2008), enquanto que o fedegoso forma agrupamentos que dificultam o estabelecimento de outro vegetal (CÂNDIDO et al., 2010).

Nas folhas de picão preto são encontrados vários compostos do metabolismo secundário como os

*email: tanismaresilva@unemat.br 
fenóis, taninos, terpenos e flavonóides que podem causar efeito alelopático (ARANTES et al., 2005). Entre os efeitos alelopáticos podem ser citadas a oxidação da radícula nas plântulas de alface, e alta percentagem de plântulas anormais, com sintomas visuais de escurecimento na ponta da radícula e, consequentemente, a degradação de seus tecidos (BACH et al., 2010). Em relação ao fedegoso, foram isolados os compostos de antraquinonas no extrato bruto das partes aérea e subterrânea (KIM et al., 2004), flavonóides (VIEGAS et al., 2006), compostos fenólicos e proantocianidinas (Luximon et. al., 2002 apud CÂNDIDO et al., 2010), associados diretamente com efeito inibitório no crescimento da alface e cebola.

Face ao exposto, fazem-se necessários estudos nessa temática, haja vista a importância econômica da cultura do gergelim, sua sensibilidade à presença de espécies daninhas e a escassez de estudos sobre os efeitos alelopáticos nessa cultura.

Dessa forma, objetivou-se nesta pesquisa avaliar o potencial alelopático dos extratos de folhas de fedegoso e picão preto na germinação e desenvolvimento de plântulas de gergelim.

\section{MATERIAIS E MÉTODOS}

O experimento foi conduzido no laboratório de Fitotecnia do Curso de Agronomia, da Universidade do Estado Mato Grosso - Campus de Cáceres. Foram utilizadas sementes de gergelim, cultivar BRS Seda Safra 2018, com 98\% de pureza, produzidas no campo experimental da Empaer, localizada no município de Cáceres.

Para a preparação dos extratos, as folhas recém colhidas de plantas de Bidens pilosa L. (picão preto) e Senna occidentalis L. (fedegoso) foram secas em estufa por 24 horas a $50^{\circ} \mathrm{C}$, conforme Oliveira et al., (2004). As folhas previamente secas foram trituradas em um moinho "tipo willey" até a obtenção de um pó que foi misturado em água na proporção de $1 \mathrm{~g} / 10 \mathrm{~mL}$ e mantida em frascos fechados durante 24 horas.

Após esse período, a mistura foi filtrada, obtendo o extrato aquoso concentrado (100\%). A partir desse extrato, foram realizadas diluições nas seguintes concentrações 10, 30, 50 e 70\% (GUSMAN et. al., 2011), tendo como controle apenas água destilada.

Para avaliar o efeito da alelopatia foi realizado o teste de germinação, em que 200 sementes de gergelim foram tomadas ao acaso da porção de sementes puras, e distribuídas em 4 repetições de 50 sementes em caixa acrílica (11x11) sobre papel mata borrão previamente umedecido 2,5 vezes o peso do papel com o extrato vegetal. Em seguida foram levadas à incubadora tipo BOD com fotoperíodo de 12 horas e temperatura de $25^{\circ} \mathrm{C}$. Realizou-se a primeira contagem ao terceiro dia e a última ao sexto dia após a semeadura. Os resultados foram expressos em porcentagem de plântulas normais (BRASIL, 2009)

Juntamente com o teste de germinação foram realizadas contagens diárias das sementes germinadas e calculado o índice de velocidade de germinação através da fórmula proposta por Maguire (1962). Após o término do teste efetuou-se a medição de comprimento de hipocótilo e radícula $(\mathrm{cm})$ das plântulas normais, com auxílio de um paquímetro.

$\mathrm{O}$ delineamento experimental utilizado foi inteiramente casualizado, no esquema fatorial de $2 \mathrm{x}$ 5 (fedegoso e picão preto $\mathrm{x}$ cinco concentrações 0,10 , 30,50 e $70 \%$ ) com quatro repetições.

Os dados obtidos foram submetidos à análise de variância e as médias foram comparadas pelo teste $\mathrm{F}$ a $5 \%$ de probabilidade e regressão utilizando o programa estatístico Sisvar 5.0 (FERREIRA, 2000).

\section{RESULTADOS E DISCUSSÃO}

Os aleloquímicos agem de maneiras diversas dependendo do ambiente e do estádio de desenvolvimento em que a planta alvo se encontra, e seus efeitos podem ser variados, dependendo do local em que estão atuando.

Ao utilizar os extratos aquosos das espécies invasoras em estudo, observou-se redução da germinação das sementes (Figura 1), do índice de velocidade de germinação (Figura 2), e no comprimento do hipocótilo (Figura 3) e da radícula (Figura 4) com o aumento da concentração.

Houve diferença significativa entre as concentrações do extrato aquoso de fedegoso e picão preto, sobre a germinação das sementes de gergelim onde os valores se ajustaram a regressão linear descrente e quadrática. Isso evidencia que as diferentes concentrações do extrato foram eficientes para causar efeito alelopático sobre a germinação.

A tendência de redução do processo germinativo na presença do extrato aquoso de picão preto sob os efeitos dos aleloquímicos no extrato ficaram mais evidentes a partir da concentração de $30 \%$. 


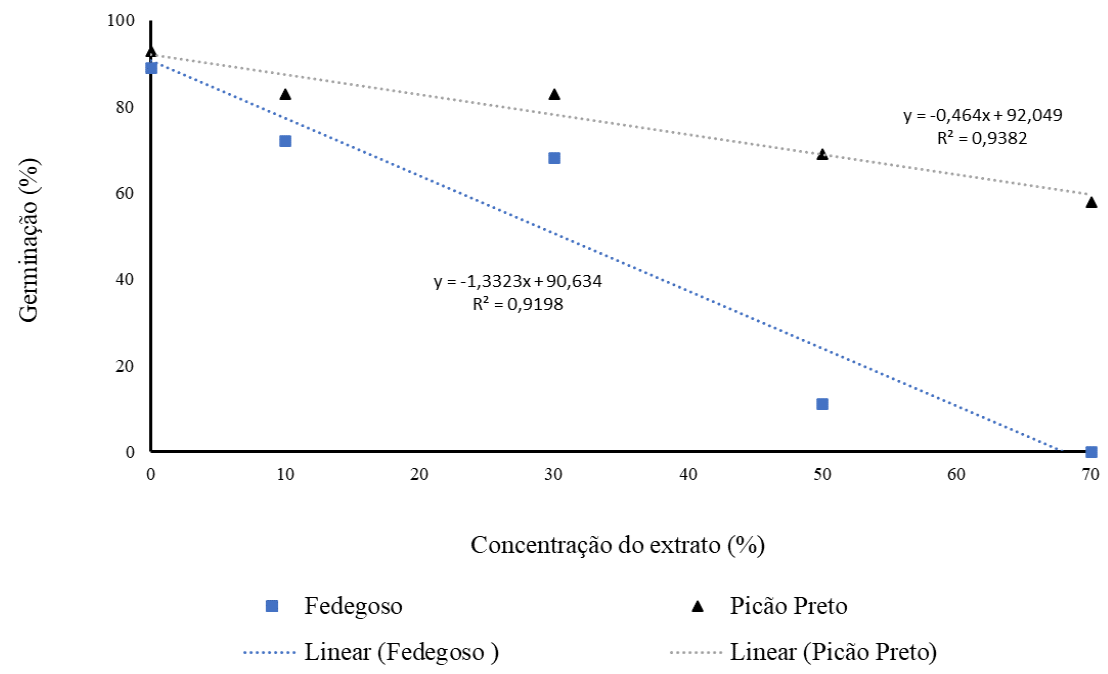

Figura 1 - Porcentagem de germinação de sementes de gergelim submetidas a diferentes concentrações de extrato aquoso de folhas de picão preto e fedegoso

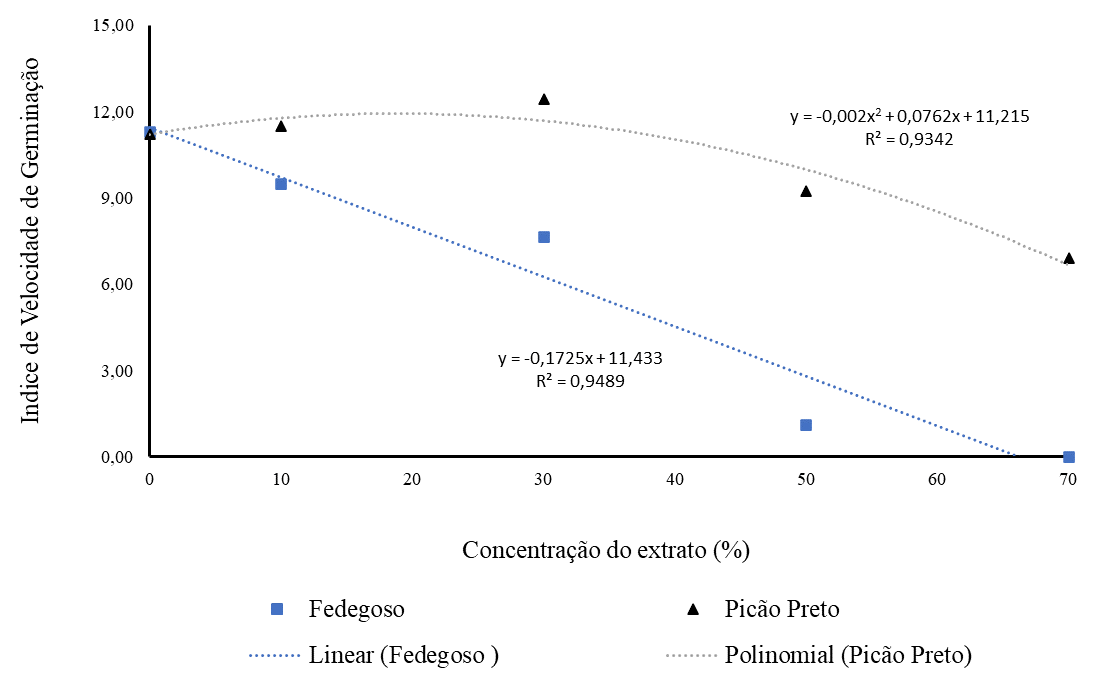

Figura 2 - Indice de velocidade de germinação (IVG) de sementes de gergelim submetidas a diferentes concentrações de extrato aquoso de folhas de picão preto e fedegoso.

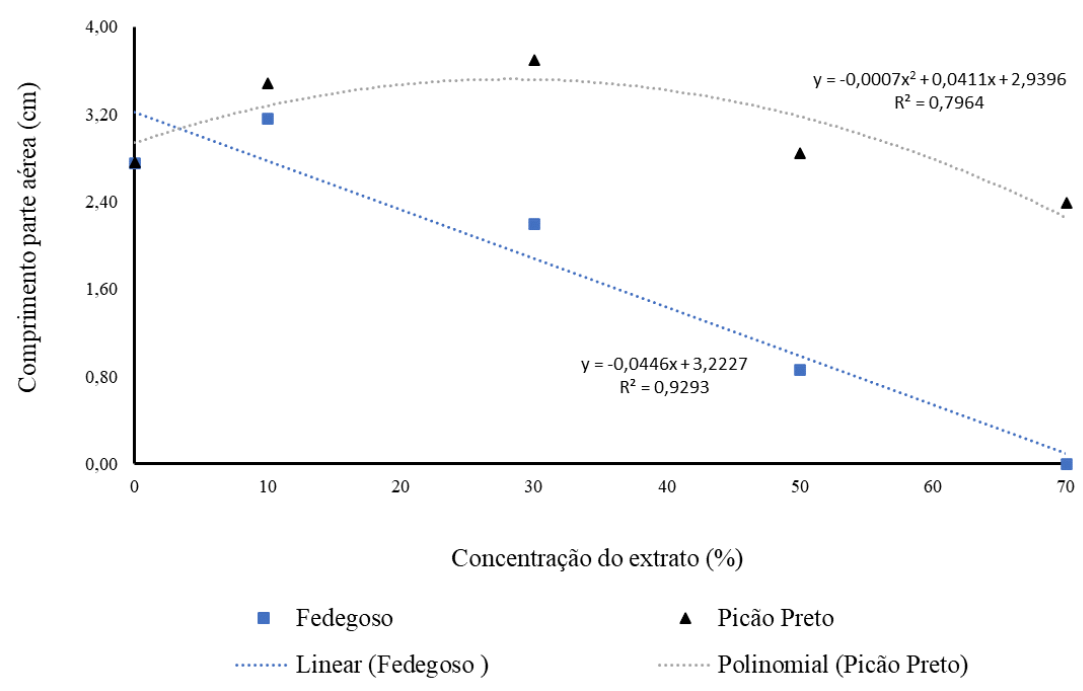

Figura 3 - Comprimento de hipocótilo de plântulas de gergelim submetidas a diferentes concentrações de extrato aquoso de folhas de picão preto e fedegoso. 


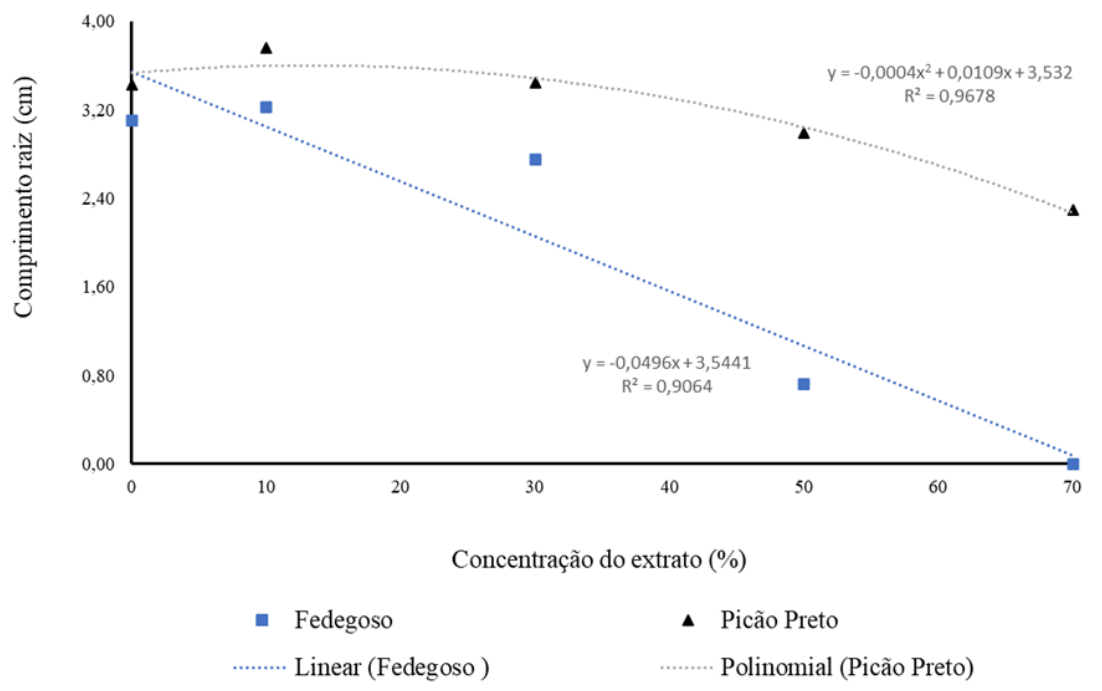

Figura 4 - Comprimento de radícula de plântulas de gergelim submetidas a diferentes concentrações de extrato aquoso de folhas de picão preto e fedegoso.

O fedegoso foi a espécie invasora que mais afetou o processo germinativo, com decréscimo na germinação a partir do extrato de $10 \%$ e com inibição na germinação das sementes de gergelim na concentração de $70 \%$. Este fato pode estar associado à presença de substâncias inibitórias de várias classes de compostos, a exemplo de antraquinonas e flavonoides. Esses constituintes são mais frequentes na maioria das espécies do gênero Senna (CÂNDIDO et al., 2010).

A velocidade de germinação (Figura 2) foi influenciada pelas diferentes concentrações do extrato. Na medida em que se eleva a concentração do extrato do fedegoso há redução do índice de velocidade de germinação chegando a zero na concentração de $70 \%$, comportamento semelhante a germinação.

Diferentemente da tendência linear, o tratamento com a solução de picão preto foi menos danoso. Esse atraso observado no tempo de germinação pode estar associado aos efeitos dos aleloquímicos, que podem atuar de forma isolada ou sinérgica, alterando os diferentes processos fisiológicos da semente (GOMES, 2016). Essa mesma tendência foi observada para os resultados do comprimento do hipocótilo (Figura 3) e da radícula (Figura 4).

A redução no tamanho da radícula e hipocótilo pode ser em função da ação de alcalóides e/ou cumarinas, que são aleloquímicos que apresentam alta toxicidade, afetando o crescimento, desenvolvimento e o ciclo celular da planta (ABENAVOLI et al., 2006; CARVALHO, 2012).

$\mathrm{O}$ maior comprimento radicular ocorreu na concentração de $10 \%$ quando se utilizou extrato de picão preto. À medida que aumentou a concentração da solução, houve redução no comprimento da parte aérea e radicular. Esse fato evidencia que os possíveis compostos alelopáticos envolvidos atuam sobre o desenvolvimento das plântulas. Mesmo que ocorra a germinação, eles influenciam as estruturas de crescimento da planta. O crescimento inicial da radícula é mais sensível por ficar em contato direto com o substrato. Em virtude desse fato, Lemos et al. (2009) consideram a interferência no desenvolvimento da radícula um dos melhores indicadores para o estudo de extratos vegetais com potencial alelopático. A inibição do comprimento da parte radicular e aérea foi verificada quando foi utilizada a concentração de $70 \%$ do extrato de fedegoso.

\section{CONCLUSÕES}

$\mathrm{O}$ extrato de picão preto inibe a germinação e vigor de sementes de gergelim em concentrações superiores a $30 \%$. Já para o extrato de fedegoso a partir da concentração de $10 \%$ a qualidade da semente é afetada.

$\mathrm{O}$ extrato de fedegoso possui maior efeito alelopático que o picão preto.

\section{REFERENCIAS}

ARAÚJO, T. F. M. Potencial alelopático de espécies arbóreas sobre a germinação e crescimento inicial do gergelim. 2016. 21 f. Trabalho de Conclusão de Curso (Graduação em Agronomia) - Universidade Federal da Paraíba, Areia.

ARANTES, M. C. B.; OLIVEIRA, L. M. G.; FREITAS, M. R. F.; SILVA, L. N. M.; NOGUEIRA, J. C. M.; PAULA, J. R.; BARA, M. T. F. Estudo farmacognosticos do Cyperus rotundus L. Revista Eletrônica de Farmácia, Goiânia, v. 2, n. 2, p. 17-20, 2005.

ABENAVOLI, M.; CACCO, G.; SORGONÁ, A.; MARABOTTINI, R.; PAOLACCI, A.; CIAFFI, M.; BADIANI, M. The inhibitory effects of coumarin on the germination of durum wheat (Triticum turgidum ssp. 
durum, cv. Simeto) seeds. Journal of Chemical Ecology, New York, v. 32, n. 2, p. 489-506, 2006.

BRASIL. Ministério da Agricultura, Pecuária e Abastecimento. Regras para análise de sementes. Ministério da Agricultura, Pecuária e Abastecimento. Secretaria de Defesa Agropecuária. Brasília: MAPA/ACS, 2009. 395p.

BACH, T. F; SILVA, T. A. C. Efeito alelopático de extrato aquoso de boldo e picão preto sobre a germinação e desenvolvimento de plântulas de alface. Revista Cultivando o Saber, Cascavel, v. 3, n. 2, p. 190 - 198, 2010.

CARVALHO, P.C. Plantas de cobertura no controle de infestantes no sistema orgânico de produção. 2012. 183f. Dissertação (Mestrado Agronomia/Fitotecnia). Universidade Federal de Lavras, Lavras.

CÂNDIDO, A. C. S.; SCHIMIDT, V.; LAURA, V. A.; FACCENDA, O.; HESS, S. C.; SIMIONATTO, E.; PERES, M. T. L. P. Potencial alelopático da parte aérea de Senna occidentalis (L.) Link (Fabaceae, Caesalpinioideae): bioensaios em laboratório. Acta Botanica Brasilica, São Paulo, v. 24, n. 1, p. 235-242, 2010.

ARRIEL, N. H. C.; BELTRÃO, N. E. M.; FIRMINO, P. T. Gergelim: $O$ produtor pergunta, a Embrapa responde. Brasília, DF: Embrapa, 2009, 209p.

FERREIRA, A. G; AQUILA, M. E. A. Alelopatia: uma área emergente da ecofisiologia. Revista Brasileira de Fisiologia Vegetal, Lavras, v. 12, p. 175 - 204, 2000. Edição especial.

GOMES, A. B. Potencial alelopático de extratos de folhas de Geonoma schottiana (Arecaceae). 2016. $86 \mathrm{f}$. Dissertação (Mestrado em Biologia Vegetal Universidade Federal do Espírito Santo, Vitória.
GUSMAN, G. S.; YAMAGUSHI, M. Q.; VESTENA, S. Potencial alelopático de extratos aquosos de Bidens pilosa L., Cyperus rotundus L. e Euphorbia heterophylla L. Iheringia Série Botânica, Porto Alegre, v. 66, n. 1, p. 87 $-98,2011$.

KIM, Y. M.; LEE, C. H.; KIM, H. G.; LEE, H.S. Anthraquinonas isolated from Cassia tora (Leguminosae) seed show an antifungal property against phytopathogenic fungi. Journal Agricultural and Food Chemistry, Washington, v. 52, p.6096-6100, 2004.

LEMOS, J. M.; BERTUOL, P.; CORTEZE, O.; GUIMARÃES, V. F. Efeito alelopático do extrato aquoso de folha de pinhão manso (Jatropha curcas L.) sobre a germinação e desenvolvimento inicial de alface (Lactuca sativa cv. Grand Rapids). Revista Brasileira de Agroecologia, Rio de Janeiro, v .4, n. 2, p. 70-88, 2009.

MAGUIRE, J. D. Speed of germination: aid in selection and evaluation for seedling emergence and vigor. Crop Science, Madison, v. 2, n. 2, p.176-177, 1962.

OLIVEIRA, S. C. C.; FERREIRA, A. G.; BORGHETTI, F. Efeito alelopático de folhas de Solanum lycocarpum A. St.-Hil. (Solanaceae) na germinação e crescimento de Sesamum indicum L. (Pedaliaceae) sob diferentes temperaturas. Acta Botanica Brasilica, São Paulo, v. 18, n. 3, p. 401-406, 2004.

RABELO, G. O.; FERREIRA, A. L. S.; YAMAGUSHI, M. Q.; VESTENA, S. Potencial alelopático de Bidens pilosa L. na germinação e no desenvolvimento de espécies cultivadas. Revista Científica da Faminas, Muriaé, v. 4, n. 1, p. 33-43, 2008.

VIEGAS JUNIOR, C. et al. Aspectos químicos, biológicos e etnofarmacológicos do gênero Cassia. Química Nova, São Paulo, v. 29, n. 6, p. 1279-1286, 2006 